\title{
The Deformation Microstructure and Eutectic Melting Activation Energy of AZ91D Alloy
}

\author{
Wang Wuxiao*, Dong Zhiqiao, Fan Zhikang and Kang Chunsheng
}

Xi'an University of Technology, Xi'an Shaanxi 710048, P.R. China

\begin{abstract}
The effect of deformation degree on deformation microstructure in the preparation of semi-solid AZ91D alloy billet by Strain Induced Melt Activated (SIMA) process was studied and the relationship between deformation degree and eutectic melting activation energy was studied by Differential Scanning Calorimetry (DSC). The results showed that with an increase in deformation degree, the original microstructure of the alloy changed from dendrites to fragmentary grains where there were twins and dislocations. When the deformation degree was $40 \%$, the decreased amount of eutectic melting activation energy was not significant. Melting point of eutectic decreased slightly with increasing deformation degree.
\end{abstract}

Keywords: AZ91D alloy, SIMA, deformation degree, eutectic melting activation energy, deformation microstructure, DSC.

\section{INTRODUCTION}

AZ91D alloy has a broad application in industry due to its high strength-to-weight ratio and good castability [1,2]. However, since magnesium has high chemical activity, and propensity to oxidative burning, protective measures are needed during melting. The semi-solid forming (SSF) process is an advanced net-shape forming technology in which components are formed in the semi-solid state of the alloy. Because the process is characterized by low forming temperature, less energy consumption, reduced solidification shrinkage and long mold life, it has attracted considerable attention [3]. The preparation of semi-solid slurry is critical in SSF. Apart from mechanical and electromagnetic stirring methods [4-7], there is SIMA process for preparing semisolid slurry $[8,9]$. SIMA process is used to extrude, draw or compress the ingots with dendrites prepared by conventional casting, and then the ingots are heated to and isothermally held in a semi-solid state for a certain period in order to transform the primary dendrites into spherical grains. Unlike other methods, alloy processing in SIMA does not require special melt treatment. This method is particularly suitable for the preparation of semi-solid magnesium alloy. The current research on the preparation of semi-solid slurry by SIMA process has mainly concentrated on the evolution of non-dendrite microstructure [3, 10-13]. However, little has been reported on the selection of deformation degrees of billets and quantitative analysis of distortion energy stored in alloy with different deformation degrees.

The existence of distortion energy due to deformation of specimens makes the activation energy of atoms change markedly when the alloy transforms from liquid to solid, especially in eutectic transition. Therefore, this paper analyses the deformation microstructure and the relationship between deformation degree, eutectic melting activation energy and distortion energy by DSC. A proper deformation degree

*Address correspondence to this author at the Xi' an University of Technology, Xi' an Shaanxi 710048, P.R. China; Tel: +86-029-82312557; Fax: +86029-82312994; E-mail: wangwuxiao@163.com; wangwx@xaut.edu.cn can be chosen in the preparation of billets by SIMA process which can provide a theoretical basis for the selection of process parameters in the preparation of semi-solid magnesium alloy billets.

\section{MATERIALS AND METHODOLOGY}

The material used for the experiments is AZ91D alloy (8.5 9.5wt.\%Al, 0.45 0.90wt.\%Zn, $\leq 0.17$ wt. \%Mn, $\leq 0.05$ wt. \% $\mathrm{Si}, \leq 0.025 \mathrm{wt} . \% \mathrm{Cu}, \leq 0.001 \mathrm{wt} . \% \mathrm{Ni}, \leq 0.004 \% \mathrm{Fe}$ and $\mathrm{Mg}$ balance). The deformation degree of the billet height was used to specify the degree of deformation. The deformation degree is defined from $\varepsilon=\left(\mathrm{H}_{0}-\mathrm{H}\right) / \mathrm{H}_{0} \times 100 \%$, where $\mathrm{H}_{0}$ is the height of the bar before deformation ( $\mathrm{mm}$ ) and $\mathrm{H}$ is the height of the bar after deformation $(\mathrm{mm})$. Bars were processed into five different sizes $(\varphi 45.7 \mathrm{~mm} \times 77.8 \mathrm{~mm}, \varphi 42.9 \mathrm{~mm} \times 87.5 \mathrm{~mm}, \varphi 40.2 \mathrm{~mm} \times$ $100 \mathrm{~mm}, \varphi 37.2 \mathrm{~mm} \times 116.7 \mathrm{~mm}$ and $\varphi 33.9 \mathrm{~mm} \times 140.0 \mathrm{~mm})$ respectively, the corresponding deformation degrees were $10 \%$, $20 \%, 30 \%, 40 \%$, and $50 \%$. The bars were compressed into $\varphi 48 \mathrm{~mm} \times 70 \mathrm{~mm}$ billets on a YJ32- 315A hydraulic pressure machine after heating to $623 \mathrm{~K}$ and holding for $60 \mathrm{~min}$. Specimens for metallography were obtained from the test bars after deformation. Samples for DSC and TEM were also prepared. The deformation microstructure was observed by optical microscope and crystal defects were analyzed by JEM 200CX TEM. The DSC2910 differential scanning calorimeter made by TA Company was used in the DSC test. During the experiment high-purity $\mathrm{N}_{2}$ was flushed at a rate of $60 \mathrm{ml} / \mathrm{min}$, and three different heating rates $(5 \mathrm{~K} / \mathrm{min}, 10 \mathrm{~K} / \mathrm{min}$, and $15 \mathrm{~K} / \mathrm{min})$ were adopted to test the specimens with different deformation degrees.

\section{RESULTS AND DISCUSSION}

\subsection{Effect of Deformation Degree on Deformation Micro- structure}

Fig. (1) shows the deformation microstructure of AZ91D alloy with different deformation degrees. Fig. (1a) displays the original casting microstructure, in which a large number of grey white areas are primary precipitates of the $\alpha$-phase $\mathrm{Mg}$ dendrite and grey black areas are the non-equilibrium eutectic microstructure of intermetallic compound $\beta$ - 
$\mathrm{Al}_{12} \mathrm{Mg}_{17}$. Because of the lower deformation degrees, the microstructure in Fig. (1b) is basically dendritic and the deformed features are not obvious. When the deformation degree is $20 \%$ (Fig. 1c), dendrite arms become thinner and longer in a certain direction after stretching, and a significant deformation characteristic become evident. When the deformation degree is $30 \%$ (Fig. 1d), fracture and elongation of dendrites are aggravated as the deformation increased, with the dendrites oriented almost parallel to a direction normal to applied stress. Additionally, the distance between the dendrites decreases and some dendrites fracture. The reason for the dendrite fracture is that the plastic deformation of dendrites can occur and dendrite become thinner and longer in easy glide orientation during the process of deformation, vice versa, plastic deformation of dendrite in difficult glide orientation is hard to occur and only has one way to deform that is fracture. When the deformation degree increases to $40 \%$ (Fig. 1e), dendrites fractured more extensively. Some become thick and short under forces, which originally are parallel to the direction of the compression pressure, not as much obviously. The microstructure becomes into fragmentary. When the deformation degree is $50 \%$ (Fig. 1f), serious breakage is caused by the poor plastic deformation property of AZ91D alloy. The microstructure is almost changed into fragmentary grains without characteristics of dendrite previously observed. Clearly, with an increase in the deformation degree the dendrites of as-cast microstructure of AZ91D alloy were gradually changed, and finally disappeared into fragmentary grains.
The TEM images of microstructure in the deformed specimens are shown in Fig. (2). There are twins in the specimens with $20 \%$ deformation degree, and there are a large number of dislocations in grains of specimens when deformation degree is $50 \%$. The existences of these deficiencies have caused distortions in the lattice of the alloy. Distortion energy is stocked which makes the internal energy of the system have an increase then the system is in the thermodynamic instability state. During the subsequent process of heating and insulation, the dislocations can provide a convenient access to the atoms activated by thermal diffusion. On the other hand, as atomic kinetic energy increases, climb and slip of dislocation is prone to take place, and the atomic diffusion is prompted. Meanwhile, the accumulation of defects themselves is apt to disrupt dendrites.

\subsection{Analysis for DSC Curves and Melting Point}

Fig. (3) indicates the DSC curves during the heating process at the heating rate of $10 \mathrm{~K} / \mathrm{min}$ of the specimens with $20 \%$ deformation degree. Two significant endothermic peaks can be seen. The lower temperature endothermic peak is sharp and the temperature range occupied is narrow. However, the higher temperature endothermic peak is relatively flat and wide. According to the microstructure of the AZ91D alloy, the lower temperature endothermic peak is corresponding to melting of eutectic microstructure $(\mathrm{Mg})+\beta$ $\left(\mathrm{Mg}_{17} \mathrm{Al}_{12}\right) \rightarrow \mathrm{L}$ and the higher temperature endothermic peak is corresponding to the melting of $\mathrm{Mg}$ solid solution.

Melting point temperature $\left(\mathrm{T}_{\mathrm{on}}\right)$ which represents the lowest temperature of the beginning of endothermic effect is
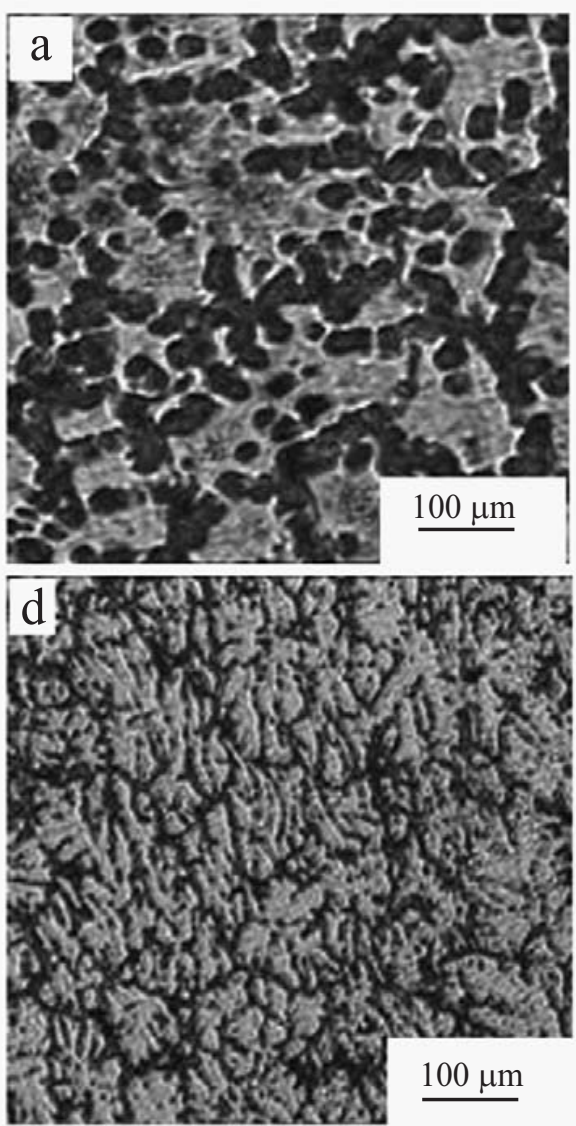
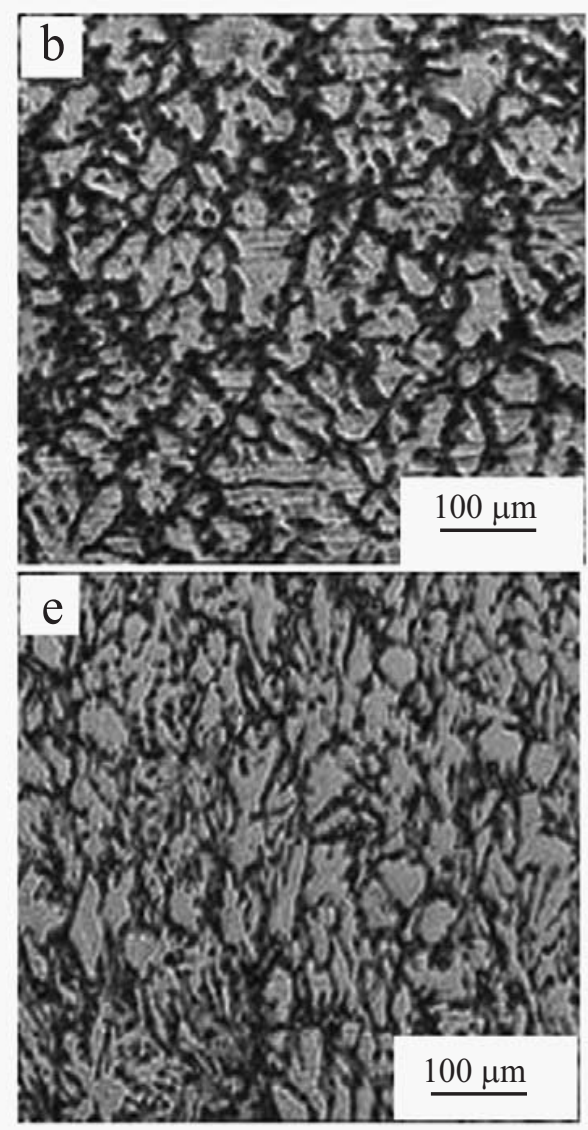
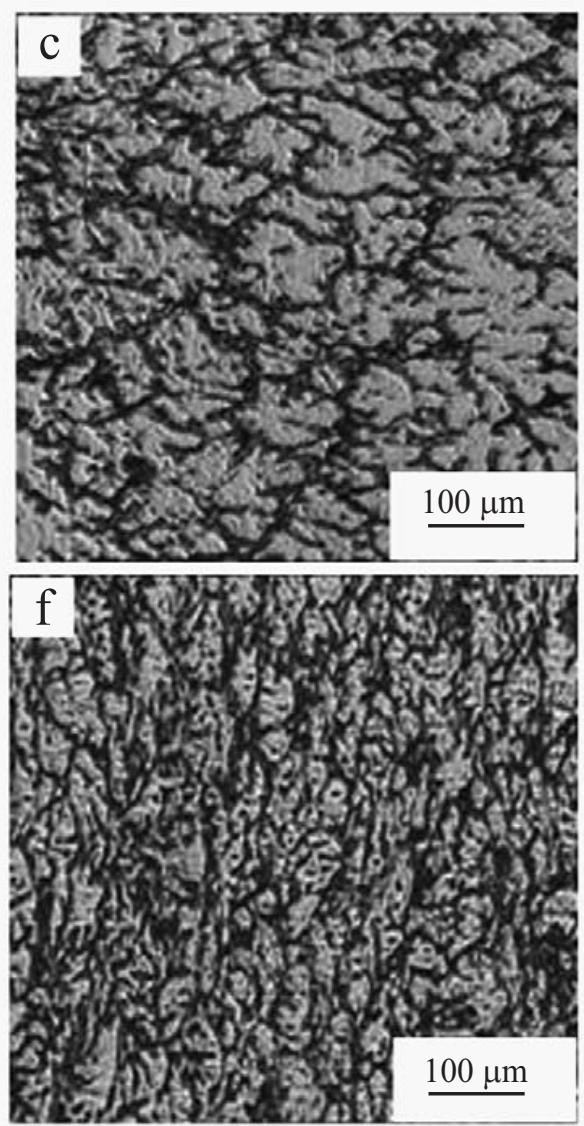

Fig. (1). Deformation microstructure of AZ91D alloy of different deformation degrees. (a) $0 \%$, (b) $10 \%$, (c) $20 \%$, (d) $30 \%$, (e) $40 \%$, (f) $50 \%$. 

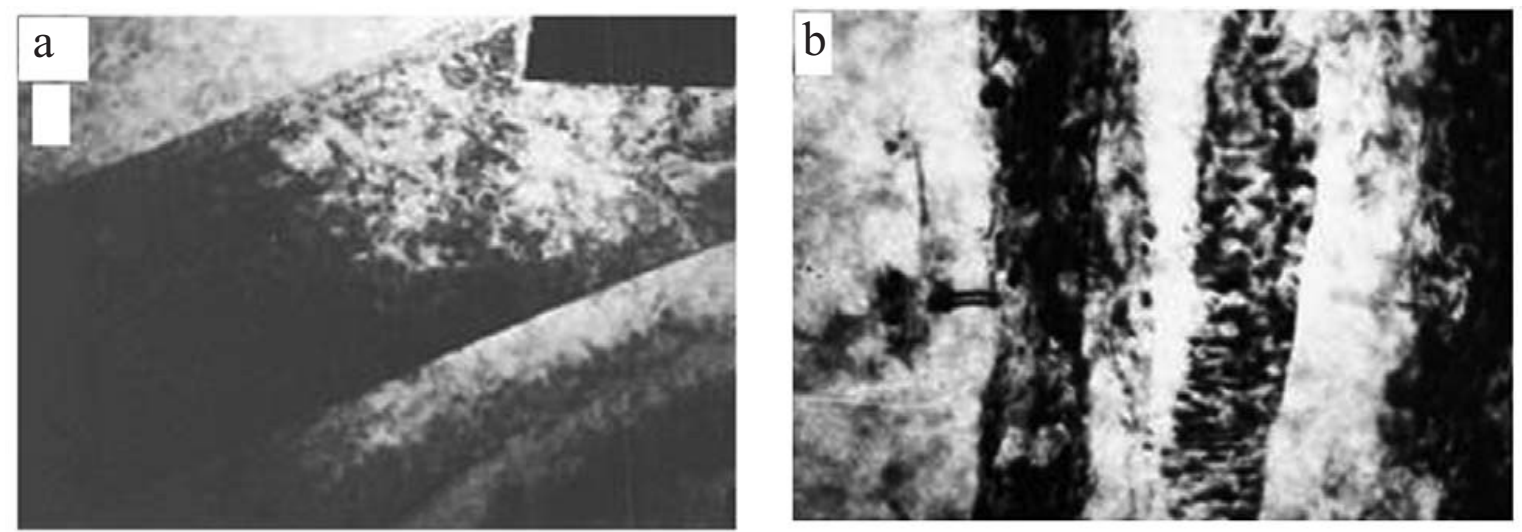

Fig. (2). Crystal defects of compressive deformed AZ91D alloy. (a) twin crystal $(\varepsilon=20 \%, 20,000 x)$, (b) dislocation $(\varepsilon=50 \%, 27,000 x)$.

one of the most important data obtained in DSC experiment. According to the regulations made by International Confederation for Thermal Analysis (ICTA), in the experiments the extrapolation method was adopted to determine the melting point, that is the temperature for the point which is the intersection of the tangent line of the largest slope point in the forefront of the peak and the baseline of extrapolation [14]. Table 1 shows the melting points with different deformation degrees and heating rates. It can be seen that the all melting points appear in the earlier stage of the eutectic transformation. With an increase in deformation the melting points decrease slightly.

\subsection{Effect of Deformation Degree on the Eutectic Melting Activation Energy and Distortion Energy}

Eutectic melting activation energy can be evaluated by the common Kissinger method [15].

Its expression is: $\mathrm{d}[\ln (\varphi / \mathrm{Tp} 2)] / \mathrm{d}(1 / \mathrm{Tp})=-\mathrm{E} / \mathrm{R}$
Where $\varphi$ is the increase rate of temperature $(\mathrm{K} / \mathrm{min}), \mathrm{T}_{\mathrm{p}}$ is the temperature of DAT peak $(\mathrm{K}), \mathrm{E}$ is the activation energy $(\mathrm{KJ} / \mathrm{mol})$ and $\mathrm{R}$ is gas constant is $8.31434 \mathrm{~J} /(\mathrm{mol} \bullet \mathrm{K})$

Table 2 displays the eutectic melting peak temperatures in DSC curves of specimens from different deformation degrees. The eutectic melting activation energy obtained by the Kissinger method is reflected in Fig. (4). The concrete method is as follows: according to the eutectic melting peak temperature $\left(\mathrm{T}_{\mathrm{p}}\right)$ obtained from different increase rates of the temperature, the curve $\ln \left(\varphi / \mathrm{Tp}^{2}\right) \sim 1 / \mathrm{T}_{\mathrm{p}}$ can be made from which the slope of line can be obtained, thus the melting activation energy can be calculated.

Distortion energy stored in alloy can be considered as the difference of melting activation energy and distortion energy between deformed and non-deformed specimens, on the basis of which the decline rate of distortion and melting activation energy of specimens from different deformation degrees can be calculated with the results shown in Table $\mathbf{3}$. It can be seen that the eutectic melting activation energy of alloy de-

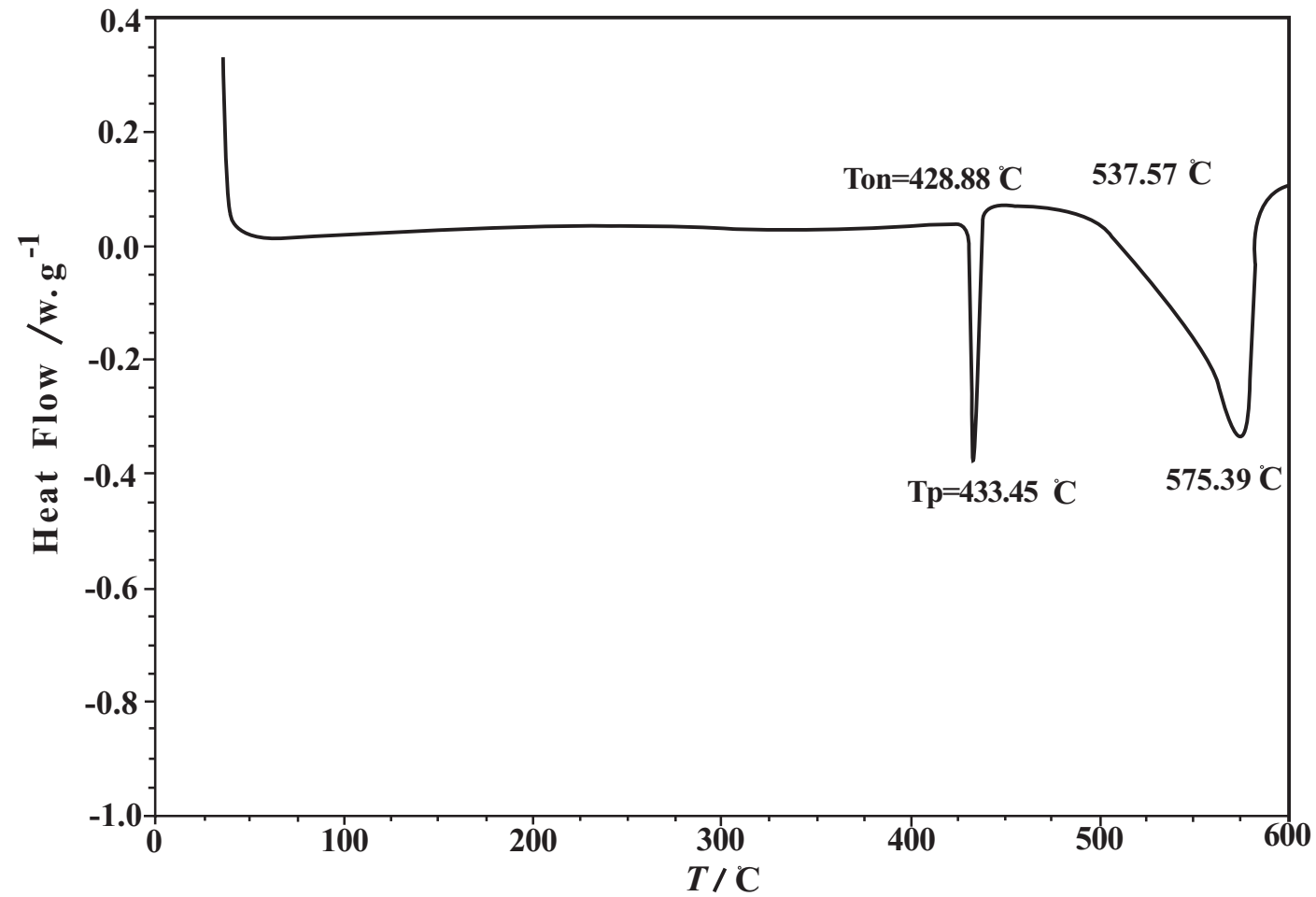

Fig. (3). DSC thermogram of AZ91D alloy with $20 \%$ deformation degree and heating rate $10 \mathrm{~K} / \mathrm{min}$. 
Table 1. Melting Point Obtained in DSC Experiments with Different Deformation Degrees

\begin{tabular}{|c|c|c|c|c|c|c|}
\hline \multirow{3}{*}{ Increase Rate of Temperature $/ \mathrm{K} \cdot \mathbf{m i n}^{-1}$} & \multicolumn{6}{|c|}{ Melting Point $\mathbf{T}_{\text {on }} / \mathbf{K}$} \\
\hline & \multicolumn{6}{|c|}{ Deformation Degree $\varepsilon / \%$} \\
\hline & $\mathbf{0}$ & 10 & 20 & 30 & 40 & 50 \\
\hline 5 & 702.86 & 701.68 & 701.55 & 701.12 & 700.26 & 700.17 \\
\hline 10 & 703.41 & 702.09 & 702.03 & 701.54 & 701.13 & 700.77 \\
\hline 15 & 703.89 & 702.47 & 702.36 & 702.01 & 701.49 & 701.32 \\
\hline
\end{tabular}

Table 2. Eutectic Melting Peak Temperatures Obtained in DSC Experiment

\begin{tabular}{|c|c|c|c|c|c|c|}
\hline \multirow{3}{*}{ Increase Rate of Temperature $/ \mathrm{K} \cdot \mathrm{min}^{-1}$} & \multicolumn{6}{|c|}{ Eutectic Melting Peak Temperatures $\mathbf{T}_{\mathbf{p}} / \mathbf{K}$} \\
\hline & \multicolumn{6}{|c|}{ Deformation Degree $\varepsilon / \%$} \\
\hline & $\mathbf{0}$ & 10 & 20 & 30 & 40 & 50 \\
\hline 5 & 706.22 & 706.01 & 705.31 & 705.07 & 704.85 & 704.78 \\
\hline 10 & 707.63 & 707.04 & 706.60 & 706.56 & 706.33 & 706.26 \\
\hline 15 & 708.71 & 708.17 & 707.83 & 707.68 & 707.44 & 707.35 \\
\hline
\end{tabular}

Table 3. Relation of Deformation Degrees and Activation and Distortion Energy

\begin{tabular}{|c|c|c|c|c|c|c|}
\hline \multirow{2}{*}{} & \multicolumn{5}{|c|}{ Deformation Degree $\varepsilon / \%$} \\
\cline { 2 - 7 } & $\mathbf{0}$ & $\mathbf{1 0}$ & $\mathbf{2 0}$ & $\mathbf{3 0}$ & $\mathbf{4 0}$ & $\mathbf{5 0}$ \\
\hline \hline eutectic melting activation energy / $\mathrm{KJ}^{-\mathrm{mol}^{-1}}$ & 1994.628 & 1857.570 & 1796.981 & 1734.057 & 1722.867 & 1711.420 \\
\hline distortion energy / $\mathrm{KJ}^{-1} \mathrm{~mol}^{-1}$ & 0 & 137.058 & 197.647 & 260.571 & 271.761 & 283.208 \\
\hline decline rate of activation energy & $0 \%$ & $6.87 \%$ & $9.91 \%$ & $13.06 \%$ & $13.62 \%$ & $14.20 \%$ \\
\hline
\end{tabular}

creases with increasing deformation, that is, the alloy becomes easier to change into liquid during the eutectic transformation. It also can be seen that the relationship between the decline of the activation energy and deformation degree is not in line, because activation energy was reduced by 13 . $06 \%$ when the deformation degree reached $30 \%$, and when deformation degree was $40 \%$ the activation energy reduced only by $0.56 \%$. In actual production deformation degree higher than $40 \%$ is meaningless. Firstly, high quality of deformation equipment is required in experiments for billets with large deformation degree, which only can be deformed under high pressure. Secondly, the microstructure of magnesium alloy is h.c.p., and there are only three slip systems at room temperature, whose plasticity is lower than f.c.c. and b.c.c. alloys, so the larger deformation degree can often lead the specimens to rupture (the specimens with $50 \%$ deformation degree in test are easily fractured), therefore the energy stored will decrease. Lastly, in the compression condition, the most notable deformation of the specimens occurs in their middle parts, while both ends of the specimens deformed slightly, whereby leading deformation inhomogeneity degree to increase. Accordingly, when SIMA process is adopted to prepare AZ91D alloy billets, the most suitable deformation degrees of compressive deformation should be in the range of $10-30 \%$.

It can be seen from Fig. (1), that when the deformation degrees are $20 \%$ and $30 \%$, there are significant deformation characteristics, and parts of dendrite arms deform and become longer in certain direction, and that when the deformation degree is above $40 \%$, obviously deformation microstructure becomes narrower and fine, but dendrite disrupt significantly, thus releasing the stress, whereas decreasing distortion energy. There are only small amounts of dendrite (easy slip orientation dendrites) going on further tensile deformation, which make distortion energy increase slightly.

\section{CONCLUSIONS}

(1) At $623 \mathrm{~K}$, with an increase in deformation degree, the microstructure of AZ91D alloy change gradually from dendrite into slender dendrite in certain direction, and finally change into fragmentary grains in which there are dislocations and twins.

(2) The eutectic melting activation energy of the alloy and the distortion energy decrease with an increase in deformation degree. When the deformation degree is $40 \%$ the decreasing amount of eutectic melting activation energy and distortion energy are very small. The melting point declines slightly with increasing deformation degree.

(3) In the preparation of AZ91D alloy by SIMA process, the more suitable deformation degrees of compression should be in the range from $10 \%$ to $30 \%$. 


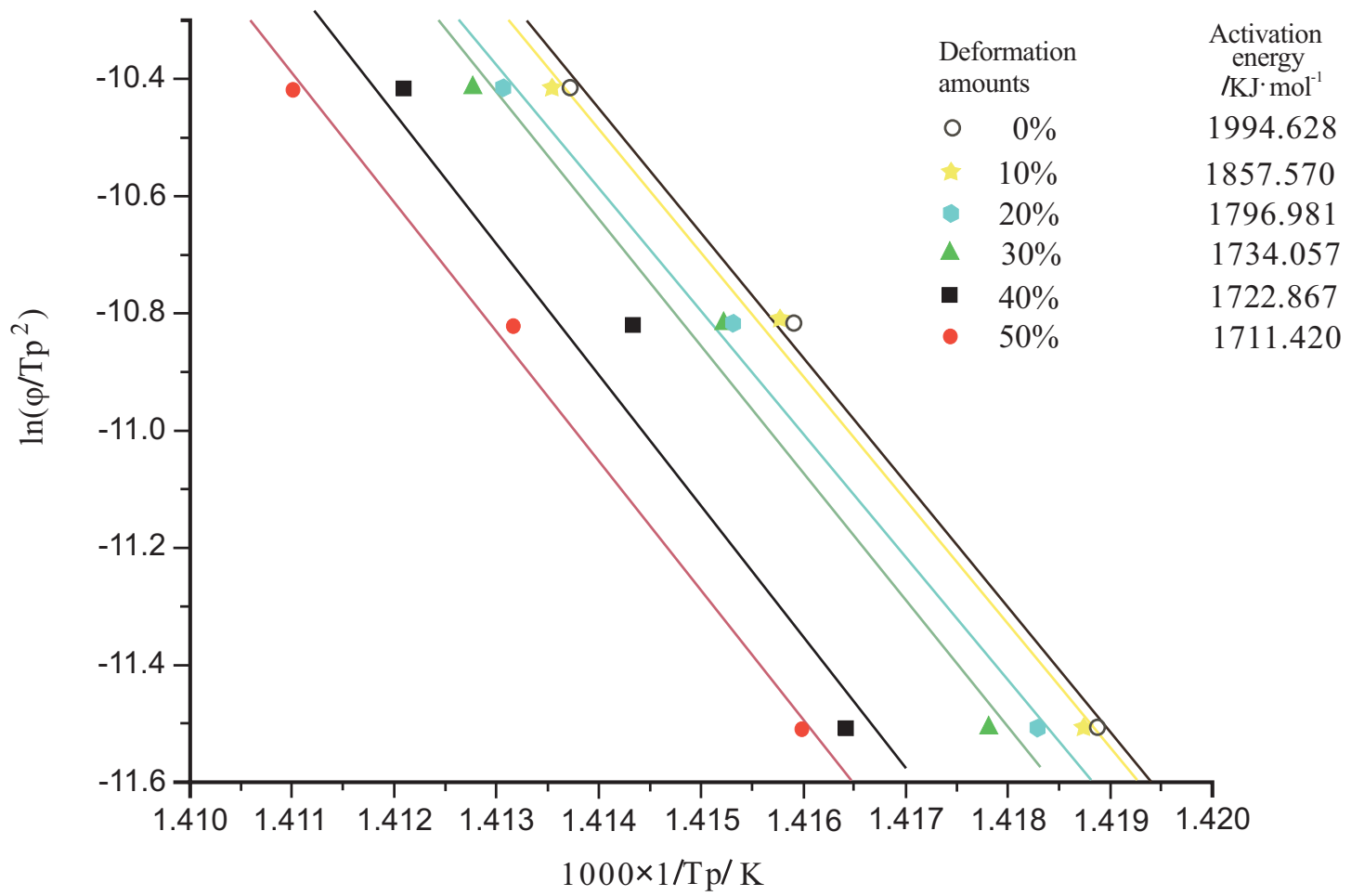

Fig. (4). Melting activation energy of the eutectic derived by Kissinger method.

\section{ACKNOWLEDGEMENT}

This work was supported by Chinese Postdoctoral Science Foundation (Grant Nos.20060391005).

\section{REFERENCES}

Elsentriecy HH, Azumi K, Konno H. Effect of surface pretreatment by acid pickling on the density of stannate conversion coatings formed on AZ91 D magnesium alloy. Surf Coat Technol 2007; 202(12): 532-7.

[2] Lü YZ, Wang QD, Zeng XQ. Effects of rare earths on the microstructure, properties and fracture behavior of $\mathrm{Mg}-\mathrm{Al}$ alloys. Mater Sci Eng A 2000; A278: 66-76.

[3] Lin HQ, Wang JG, Wang HY, Jiang QC. Effect of predeformation on the globular grains in AZ91D alloy during strain induced melt activation (SIMA) process. J Alloys Comp 2007; 431(4): 141-7.

[4] Zuo H, Liu C, Zou M. Semi-solid die casting process of motorcycle parts of ZL112Y die cast alloy. Chin J Nonferrous Metals 2003; 13(4): 949-55.

[5] Xu Y, Kang Y, Wang Z. Preparation of semi-solid slurry of AZ91D Mg Alloy. Special Casting Nonferrous Alloys 2004; (5): 12-4.

[6] Li M, Takuya T, Kenji M. Controlling microstructures of AZ31 magnesium alloys by an electromagnetic vibration technique during solidification: From experimental observation to theoretical understanding. Acta Mater 2007; 55(14): 4635-43.
[7] Yang B, Du D, Zhu X. Effects of electromagnetic stirring on microstructure of Mg-Al-Si alloy. Special Casting Nonferrous Alloys 2004; (3): 26-8.

[8] Tzimas E, Zavaliangos A. A comparative characterization of nearequiaxed microstructures as produced by spray casting, magnetohydrodynamic casting and the stress induced melt activated process. Mater Sci Eng A 2000; A289: 217-22.

[9] Luo SJ, Tian WT, Zhang GG. Structural evolution of LC4 alloy in making thixotropic billet by SIMA method. Trans Nonferrous Metals Soc China 2001; 11(4): 547-50.

[10] Tzimas E, Zavaliangos A. Evolution of near-equiaxed microstructure in the semisolid state. Mater Sci Eng A 2000; A289: 228-40.

[11] Chen T-J, Hao Y, Lu S. Influences of strains and isothermal temperatures on microstructure of ZA27 alloy during strain-induced melt activation. J Metal Heat Treat 2000; 21(1): 26-31.

[12] Liu C, Zou M, Zhang Z. Effect of semi-solid melting factors on structure and grain size of LY12 alloy in SIMA processing. Chin J Nonferrous Metals 2002; 12(3): 436-41.

[13] Jiang H, Huang Weichao, LuYalin. Microstructure evolution of semi-solid LY11 alloy by SIMA. Rare Metal Mater Eng 2004; 33(8): 869-72.

[14] Pope MI, Youde MD. Differential thermal analysis. Beijing: Beijing Normal University Publishing House 1982.

[15] Hu Rongzu, Shi Qizhen. Dynamic Thermal Analysis, Beijing: Science Press 2001.

(C) Wang Wuxiao; Licensee Bentham Open.

This is an open access article licensed under the terms of the Creative Commons Attribution Non-Commercial License (http://creativecommons.org/licenses/by$\mathrm{nc} / 3.0 /$ ) which permits unrestricted, non-commercial use, distribution and reproduction in any medium, provided the work is properly cited. 